\title{
A study on seroprevalence of HIV among women attending obstetric care in a tertiary care hospital of South India with maternal and perinatal outcomes
}

\author{
Shruthi M. N., Srinivas K. Jois* \\ Department of Obstetrics and Gynecology, Bangalore Medical College and Research Institute, Bangalore, Karnataka, \\ India
}

Received: 09 April 2018

Accepted: 02 May 2018

\section{*Correspondence:}

Dr. Srinivas K. Jois,

E-mail: srinivaskjois@gmail.com

Copyright: (C) the author(s), publisher and licensee Medip Academy. This is an open-access article distributed under the terms of the Creative Commons Attribution Non-Commercial License, which permits unrestricted non-commercial use, distribution, and reproduction in any medium, provided the original work is properly cited.

\section{ABSTRACT}

Background: HIV is prevalent in epidemic proportions in India. Identifying the target population and effective intervention reduces chances of vertical transmission and new infection. Authors studied the seroprevalence of HIV among women attending obstetric care in a tertiary care hospital of South India and associated maternal and perinatal outcomes among seropositive women.

Methods: Retrospective descriptive study of all women who were screened for HIV at Integrated Counselling and Testing Centre, Vani Vilas hospital, from January 2014 to December 2017 in their antenatal, intranatal and postnatal period. Demographic data of seropositive women, obstetric outcomes and status of children at 18 months were obtained.

Results: Of the 35,455 women who were screened, $0.28 \%$ were found positive for HIV. Percentage prevalence of HIV was highest in $2014(0.32 \%)$. Majority of the seroprevalence belonged to age group of 25-29 years (44\%), 32\% illiterates, $82 \%$ homemakers and $79 \%$ belonged to urban areas. Unknown partner status in $22 \%$ and majority were diagnosed in antenatal period (66\%). Of them $82 \%$ had favourable CD4 count. $74 \%$ of them delivered live baby. Three maternal deaths were observed and anaemia $(65 \%)$ was the major associated co-morbidity. Vaginal route was common mode of delivery (84\%). Thirteen babies required NICU admission and 6 neonates deaths were encountered. Exclusive breastfeeding was practised in $91 \%$ of live births. $62 \%$ of children were found seronegative at 18 months follow up.

Conclusions: Authors observed with adequate treatment to mother and prophylaxis to the baby, the burden of vertical transmission can be significantly reduced.

Keywords: Human immunodeficiency virus, Obstetric outcomes, Seroprevalence

\section{INTRODUCTION}

It has been estimated that 2.1 million people are living with HIV in India. Its prevalence being $0.27 \%$. Of these $39 \%$ are women and $7 \%$ are children aged $<15$ years. ${ }^{1}$ Approximately about 49000 of women infected with HIV conceive every year and subsequently deliver with or without proper prophylaxis to prevent vertical transmission. ${ }^{2,3}$

It is known from various studies that the mother to child transmission of HIV is a major route of infection among children. The incidence, prevalence along with the burden of the disease can be substantially curtailed by 
proper care and treatment during pregnancy and delivery. As pregnancy itself increases the chances of progression of the disease, proper treatment to the mother helps in improving her health. The linchpin in achieving this goal is by identifying the target population. Since many of the patients infected with HIV are asymptomatic, adoption of universal counselling and screening helps in identifying the target population.

A child can acquire HIV infection from its mother during pregnancy, labour/delivery and during breast feeding. Without any proper intervention/treatment, the risk of transmission from infected women to her child is estimated to be around 20-45\%. After proper intervention and use of ART (anti retroviral therapy) in its proper dosage and duration, the chances of vertical transmission can be reduced to $10 \%{ }^{1}$

Three drug regimen including, Tenofovir + Lamivudine + Efavirenz to all pregnant women irrespective of CD4 count and WHO stage as directed by NACO is currently practised in India. Antiretroviral prophylaxis with Nevirapine to all infants from birth upto a minimum period of 6 weeks is indicated. ${ }^{1}$

To the best our knowledge, this is one of the largest study on the seroprevalence of HIV among women attending obstetric care in a tertiary care hospital of South India with maternal and perinatal outcomes. Apart from the demographics, present study also reflects the impact of three drug regimen suggested by NACO (National AIDS Control Organisation) on vertical transmission.

\section{METHODS}

This is a retrospective descriptive study of all women who were screened for HIV at ICTC (Integrated Counselling and Testing Centre), Vani Vilas hospital, from January 2014 to December 2017 in their antenatal, natal and postnatal period.

All the pregnant women attending the antenatal clinic of Vani Vilas hospital were counselled on the importance of screening for HIV with an opt out strategy. Blood sample was collected from the pregnant woman who consented for the test. Rapid tests were performed including triline, tridot and ELISA and the patients who were found positive were subsequently counselled. Confidentiality of the data was maintained at all time. The patient was advised on proper antenatal care, ART regimen and treatment, hospital delivery, universal precautions and neonatal prophylaxis including complimentary feeding.

Those who presented without the test in labour, or post delivery were also tested, the reports confirmed later and referred to ICTC for further advice.

In present study, authors included all the screened women who were found seropositive for HIV in their antenatal, natal and postnatal period. Various demographic data from those who were found seropositive was collected. The details of events during antenatal, intranatal and post natal period, the perinatal outcome was also noted. Data was subsequently analyzed in Microsoft excel along with calculation of relative percentages.

\section{RESULTS}

A total of 35,455 women were screened. Of these 101 were found seropositive for HIV with a percentage prevalence of $0.28 \%$. There was a declining trend in the number of women who underwent universal screening for HIV from 2014 to 2017. Percentage prevalence of HIV was highest in the year $2014(0.32 \%)$ and least in the year $2016(0.22 \%)$

Table 1: General demographic factors of seropositive pregnant women.

\begin{tabular}{|c|c|c|}
\hline Characters & $\begin{array}{l}\text { No. of } \\
\text { seropositive } \\
\text { pregnant women }\end{array}$ & Percentage \\
\hline \multicolumn{3}{|l|}{ Age distribution } \\
\hline $15-19$ yrs & 5 & 5 \\
\hline $20-24$ yrs & 37 & 37 \\
\hline $25-29$ yrs & 45 & 44 \\
\hline $30-34$ & 10 & 10 \\
\hline 35- 39 & 3 & 3 \\
\hline$>40$ & 1 & 1 \\
\hline Total & 101 & 100 \\
\hline \multicolumn{3}{|c|}{ Educational qualification } \\
\hline Illiterate & 33 & 32 \\
\hline Primary & 16 & 16 \\
\hline Secondary & 20 & 20 \\
\hline Higher secondary & 17 & 17 \\
\hline \multirow[t]{2}{*}{ College and above } & 15 & 15 \\
\hline & 101 & 100 \\
\hline \multicolumn{3}{|l|}{ Occupation } \\
\hline Homemaker & 83 & 82 \\
\hline Agricultural laborer & 3 & 3 \\
\hline $\begin{array}{l}\text { Non-agricultural } \\
\text { laborer }\end{array}$ & 12 & 12 \\
\hline \multirow[t]{2}{*}{ Skilled labor } & 3 & 3 \\
\hline & 101 & 100 \\
\hline \multicolumn{3}{|c|}{ Geographical distribution } \\
\hline Rural & 21 & 21 \\
\hline \multirow[t]{2}{*}{ Urban } & 80 & 79 \\
\hline & 101 & 100 \\
\hline
\end{tabular}

Among the women who were found to be seropositive for HIV, a majority of them belonged to age group of 25-29 years $(44 \%)$ with mean age being 25.32 years (Table 1$)$. $32 \%$ of seropositive women were illiterates (Table 1) and homemakers (82\%) (Table 1). Also, majority of these women belonged to urban areas (79\%) (Table 1).

There was relatively slightly higher prevalence of seropositive status among multigravida (55\%). Partner status was unknown in $22 \%$. Majority of the who were 
found seropositive were in antenatal period (66\%) (Table 2).

Table 2: Obstetric demographic factors of seropositive pregnant women.

\begin{tabular}{|lll|}
\hline \multicolumn{2}{|l|}{ Order of pregnancy } \\
\hline Primigravida & 45 & 45 \\
\hline Multigravida & 56 & 55 \\
\hline \multicolumn{4}{|l|}{} & 101 & 100 \\
\hline Partner positivity & status \\
\hline Positive & 40 & 40 \\
\hline Negative & 39 & 38 \\
\hline Not known & 22 & 22 \\
\hline \multicolumn{4}{l}{ Stage of detection of seropositivity } \\
\hline Prenatal & 1 & 100 \\
\hline Anc & 67 & 1 \\
\hline Labor & 28 & 66 \\
\hline Post natal & 5 & 28 \\
\hline & 101 & 5 \\
\hline
\end{tabular}

In present study $82 \%$ of seropositive women had favourable CD4 count of $>250 / \mathrm{cu} \mathrm{mm}$. Also $74 \%$ of seropositive delivered live baby. Various other pregnancy outcomes are described in details in Table 3.

Table 3: Pregnancy outcome among seropositive women.

\begin{tabular}{|lll|}
\hline Pregnancy outcome & No. of subjects & Percentage \\
\hline Abortion & 14 & 14 \\
\hline Ectopic pregnancy & 3 & 3 \\
\hline Live birth & 75 & 74 \\
\hline Stillbirth & 5 & 5 \\
\hline Maternal mortality & 1 & 1 \\
\hline Ongoing pregnancy & 3 & 3 \\
\hline Total & 101 & 100 \\
\hline
\end{tabular}

In present study, the predominant mode of delivery was vaginal route among seropositive women (84\%). Three maternal deaths were observed during our study period with 2 in the post natal period and 1 in the antenatal period.

Table 4: Pregnancy associated major co-morbidities among seropositive women who delivered.

\begin{tabular}{|l|l|}
\hline $\begin{array}{l}\text { Co-morbidities associated with } \\
\text { pregnancy }\end{array}$ & $\begin{array}{l}\text { No. of } \\
\text { subjects }\end{array}$ \\
\hline Hypertension & 6 \\
\hline Eclampsia & 1 \\
\hline Gdm & 4 \\
\hline Anaemia & 55 \\
\hline Placenta previa & 1 \\
\hline Abruption & 1 \\
\hline
\end{tabular}

Pregnancy associated major co-morbidities were noted in 68 of 84 women who delivered $(81 \%)$. Anaemia was the major associated co-morbidity noted in 55 seropositive women. Various other associated co-morbidities are as described in Table 4.

Table 5: Causes of NICU admission.

\begin{tabular}{ll|} 
Causes of NICU admission & Number of neonates \\
\hline Respiratory distress & 6 \\
Preterm care & 4 \\
\hline Sepsis & 2 \\
\hline Congenital anomaly & 1 \\
\hline Total & 13 \\
\hline
\end{tabular}

Of the 75 live birth, 13 babies necessitated NICU admission (17\%) with respiratory distress being the main cause for NICU admission (Table 5). There were 6 neonatal deaths and 4 of them died in early neonatal period.

Table 6: Child status at 18 months of age.

\begin{tabular}{|lll|}
$\begin{array}{l}\text { Child status at } \mathbf{1 8} \\
\text { months }\end{array}$ & $\begin{array}{l}\text { No. of } \\
\text { children }\end{array}$ & Percentage \\
\hline Seropositive & 2 & 3 \\
\hline Seronegative & 46 & 62 \\
\hline Death & 6 & 7 \\
\hline Not known & 9 & 12 \\
\hline Ongoing screening & 12 & 16 \\
\hline & 75 & 100 \\
\hline
\end{tabular}

Exclusive breastfeeding was practised in $91 \%$ of live births among seropositive women. With this background $62 \%$ of children were found seronegative when screened for HIV at 18 months of age. Status of the children at 18 months follow up is as described in Table 6.

Table 7: Educational status among women seeking MTP.

\begin{tabular}{|lll|}
\hline $\begin{array}{l}\text { Education among } \\
\text { women seeking MTP }\end{array}$ & $\begin{array}{l}\text { No. of } \\
\text { subjects }\end{array}$ & Percentage \\
\hline Illiterate & 1 & 9 \\
\hline Primary & 1 & 9 \\
\hline Secondary & 5 & 46 \\
\hline Higher secondary & 2 & 18 \\
\hline College and above & 2 & 18 \\
\hline & 11 & 100 \\
\hline
\end{tabular}

Among women seeking MTP (Medical termination of pregnancy), $91 \%$ were literates and their educational status is as described below in the Table 7.

\section{DISCUSSION}

As HIV is prevalent in epidemic proportions in India, blocking the chain of vertical transmission helps in significantly reducing the rate of new infections. Inclusion of appropriate strategies by NACO like universal screening, triple drug regimen for seropositive 
mother, universal precautions and neonatal prophylaxis has contributed significantly in the recent trends of declining new HIV infections. It has also helped in maintaining the health of the seropositive mother. Also, proper counselling among seropositive women has helped in eliminating unwanted pregnancies and thereby reducing the chances of new infection. In present study we evaluated the various demographic factors among seropositive women along with maternal and perinatal outcomes which may reflect the effectiveness of various strategies adopted under PPTCT (Prevention of ParentTo-Child Transmission).

According to annual report of NACO 2015-16, 53.2 lakh pregnant women were tested for HIV. Among them 5856 were turned out to be seropositive $(0.11 \%) .{ }^{4}$ In present study we found percentage prevalence of seropositive status among screened women being $0.28 \%$. Percentage prevalence among other studies conducted by Swati Gupta et al ${ }^{5}$ and Ajit Kumar Nayak et al ${ }^{6}$ is $0.88 \%$ and $0.5 \%$ respectively. In another study conducted by Preetkanwal Sibia et $\mathrm{al}^{7}$ showed a seroprevalence rate of $1.03 \%$. The difference in the prevalence among various studies could be attributed to difference in sample size and also variability in the prevalence of HIV among various states in India. There was also annual variability in the percentage prevalence of HIV among screened women in present study with highest percentage in the year $2014(0.32 \%)$ and least in the year $2016(0.22 \%)$.

Majority of the seropositive women in present study belonged to age group of 25-29 years. This is in consensus with various other studies such as Ajit Kumar Nayak et al, $^{6}$ Preetkanwal Sibia et al ${ }^{7}$ and Poonam C. Sayare et al. ${ }^{8}$ This reflects the fact majority of pregnancies and deliveries happen among women belonging to this age group.

Seropositive status was noted among $32 \%$ of illiterates. This could be attributable to the ignorance on the modes of transmission and associated low socioeconomic status among illiterates acting as confounding factor in contracting infection through various means.

Majority of seropositive women in present study were homemakers $(82 \%)$. As the hospital in which study was conducted was in an urban area catering to the needs of the local urban population, majority of the seropostive women belonged to urban population $(79 \%)$.

Seropositive status in present study was more among multigravida (55\%). This is in consensus with study conducted by Nayak AK et $\mathrm{al}^{6}(62.5 \%)$ and in contrast to study conducted by Vaishali Milind Patil et al ${ }^{9}$ in which primigravida constituted majority $(53.83 \%)$. In another study conducted by Ashtagi GS et al ${ }^{10}$ seroprevalence was more among multigravid women (63.83\%). Multigravidity and closely spaced pregnancies are more common in low socioeconomic status and illiterates. Similarly, prevalence of HIV is more common among low socio economic status. So, the chances of acquiring infection is substantially increased during each pregnancy.

In present study we also tried to look into the status of the partner among seropositive women and we found $40 \%$ of partners were seropositive and declared concordant couple. This aided in counselling and subsequent treatment. Partner status was not known in $22 \%$ either due to denial for undergoing test or separated from wife or death of the partner.

The seropositive status in majority of the cases was detected during their antenatal period $(66 \%)$. This reflects the effective implementation of universal screening programme under PPTCT.

In present study $82 \%$ of seropositive women had favourable CD4 count of $>250 / \mathrm{cu} \mathrm{mm}$. Though a low CD4 count is of prognostic significance, current guidelines of PPTCT suggests for ART for seropositive women irrespective of their staging/CD4 count.

Among 101 seropositive women there were 75 live births $(74 \%)$. Fourteen of them aborted (14\%), 3 being spontaneous in their first trimester and 11 induced. Ectopic pregnancy was noted in 3 of them (3\%) and still birth in 5 of them $(5 \%)$. One of the seropositive women died during antenatal period due to eclampsia. There were 3 cases of ongoing pregnancy during the study period.

Predominant mode of delivery among seropositive women was the vaginal route $(84 \%)$. This is in contrast to a study conducted by Dadhwal $\mathrm{V}$ et al ${ }^{11}$ in which $91.5 \%$ of seropositive women had a caesarean delivery. This difference is due to the fact that most of the patients presented themselves in the late stages of labour, and caesarean section is not suggested unless obstetric indications to prevent vertical transmission as per NACO guidelines.

Three maternal deaths were noted during the study period. Two of them were during post-natal period. One of them had febrile illness and other subject had cryptococcal meningitis.

Pregnancy associated major co morbidities were noted in $81 \%$ of seropositive women who delivered with anemia being the major co-morbidity in 55 of them amounting to $65 \%$. Similar results were found in study performed by Kay Tunkyi et al. ${ }^{12}$ This could be attributable to high prevalence of anemia in pregnant women in India and due to ART which can exacerbate anemia.

Of the 75 live birth, 13 babies necessitated NICU (Neonatal Intensive Care Unit) admission (17\%) with respiratory distress being the main cause for NICU admission. Six neonatal deaths born of seropositive 
mother were recorded during study period and 4 died during early neonatal period.

Exclusive breastfeeding was practised in $91 \%$ of live births among seropositive women. This is in accordance with NACO guidelines.

At 18 months follow up seropositivity was noted among 2 children accounting to $3 \%$. In both the cases mother was not treated during her antenatal period as the status was not known and directly presented during labour. 16\% of children born to seropositive mothers have still not attained 18 months of age to complete the screening process.

Among seropositive women seeking MTP to avoid unwanted pregnancies most were literate.

\section{CONCLUSION}

Demographic characteristics illustrated in present study forms a supportive basis in understanding and formulating various targeted interventions in reducing the disease burden. Evaluation of partner status aides in counselling and subsequent treatment. Present study also forms a mirror reflection to the fact that with adequate treatment to mother and prophylaxis to the baby as directed by PPTCT, the burden of vertical transmission can be significantly reduced.

Funding: No funding sources

Conflict of interest: None declared

Ethical approval: The study was approved by the Institutional Ethics Committee

\section{REFERENCES}

1. Welfare F. Prevention of Parent to Child Transmission (PPTCT) of HIV using Multi Drug Anti-retroviral Regimen in India; National Guidelines for Prevention of Parent-to-Child Transmission of HIV. 2013;137.

2. Children UFOR, Aids UA. India: PMTCT. World Health. 2010;1-2.
3. Control A. Statement Containing Brief Activities of the Department of AIDS Control in 2013. Dep AIDS Control MoHFW, India. 2013;20.

4. National AIDS Control Organization. National AIDS Control Policy -annual report 2015-16. 2016;335-97.

5. Gupta S, Gupta R, Singh S. Seroprevalence of HIV in pregnant women in North India: a tertiary care hospital based study. BMC Infect Dis. 2007 Nov $15 ; 7: 133$.

6. Nayak AK, Jain MK, Dhivya S, Hota S. A study on prevalence of HIV infection among pregnant women attending antenatal clinic in a tertiary care hospital, Cuttack, India. Int J Comm Med Public Health. 2017 Apr 24;4(5):1504-9.

7. Sibia P, Mohi MK, Kumar A. Seroprevalence of Human Immunodeficiency Virus Among Antenatal Women in One of the Institute of Northern India. J Clin Diagn Res. 2016 Sep;10(9):QC08-QC09.

8. Sayare PC, Ambhore NA, Mantri RS, Karyakarte RP. Prevalence of HIV infection among pregnant women in a tertiary care hospital Akola, India. Int $\mathbf{J}$ Curr Microbiol Appl Sci. 2017;6:691-6.

9. Patil V, Moray A, Patil S. Ten years' trend of HIV seroprevalence among Indian pregnant women attending antenatal clinic at tertiary hospital in Dhule, Maharashtra, India. Int J Reprod Contracept Obstet Gynecol. 2016;5(5):1514-9.

10. Ashtagi GS, Metgud CS, Walvekar PR, Naik VA. Prevalence of HIV among rural pregnant women attending PPTCT services at KLE Hospital, Belgaum. Al Ameen J Med Sci. 2011;4(1):45-8

11. Dadhwal V, Sharma A, Khoiwal K, Deka D, Sarkar P, Vanamail P. Pregnancy outcomes in HIV-infected women: experience from a tertiary care center in India. Int J MCH AIDS. 2017;6(1):75-81.

12. Tunkyi K, Moodley J. Anaemia in pregnancy in a setting of high HIV prevalence rates. South African J Infect Dis. 2017;32(4):138-41.

Cite this article as: Shruthi MN, Jois SK. A study on seroprevalence of HIV among women attending obstetric care in a tertiary care hospital of South India with maternal and perinatal outcomes. Int J Reprod Contracept Obstet Gynecol 2018;7:2429-33. 